\title{
The Analysis and Research of Welding New Technology
}

\author{
Zhang Rong \\ Department of Mechanical Engineering, Dalian Vocational Technical College, Dalian, Liaoning, \\ 116037, China \\ Lzhch11993@sina.com
}

Keywords: Welding, New Technology, Computer, Robot

Abstract. Through the analysis of the application of welding new technology, leads to development trends and application of a variety of modern forming technological, with the development of computer technology, based on material forming simulation technology has become frontier and research focus of materials science and engineering disciplines.

\section{Introduction}

During the welding process the material withstands very high temperatures, and occurs complex changes in the physical, chemical, thermal, mechanical and metal science. Some special welding process harsh working conditions, such as welding preheat to $200{ }^{\circ} \mathrm{C}$ in the container, the welding on oil platforms in deep water, in the case of the nuclear reactor radiation and so on. Modern manufacturing industry to high-precision, high-quality, low-cost, quick-degree trend of development, welding technology has been proposed many newer and higher requirements, and with the development of modern industrial technology, emergence many new materials and new structures, to meet the needs of actual production, welding production increasingly used in computer and information technology to improve the welding skills, and broaden the scope of the study welding. In recent decades, a variety of energy-efficient welding methods, welding production mechanization and automation, application of new technologies such as welding robots, has brought great change to the manufacturing sector.

\section{Welding robot and intelligent}

Welding robot is a new automated welding equipment in the 1970s began to develop, now has become an important development direction of welding automation. Such as welding robots have been used in the US car production line, up to 100 vehicles per hour production speed, accuracy up to $\pm 0.1 \mathrm{~mm}$. Welding robots have also been extensive use of several automobile companies in body welding.

\subsection{Consisting of welding robot}

Fig1 shows the basic components of the welding robot. It includes two parts of robots and welding equipment. The robot is composed by robot body and control cabinet (hardware and 
software). The welding equipment (in arc welding and spot welding, for example) is composed by welding power source (including its control system), wire feeder (arc), torch (pliers) and others [1]. For intelligent robot also includes a sensing system, such as a laser or imaging sensor and its control apparatus. Figure $1 a, b$ show the basic components arc welding and spot welding.

\subsection{The main structure of welding robot}

Welding robot mechanical structure of the body there are two main forms, one of them is parallelogram structure, the other is side-mounted (tilting) structure. The main advantage of side-mounted (tilting) structure is a large range of motion of the upper and lower arm, the working space of the robot almost can reach a sphere. Therefore, this robot can work upside down on a rack to save floor space and to facilitate the activities of ground objects. However, this side-mounted robot arm structure, reducing the stiffness of the robot, generally applicable to smaller load robot for arc welding, cutting or spraying. Parallelogram robot arm which is driven by a rod. Rod and lower arm form a parallelogram sides bar, hence the name. Parallelogram robot workspace early development of is relatively small (limited to the front portion of the robot), is difficult to work upside down. But since the end of the 20th century, 80 generations later stage, the development of new parallelogram robot, has been able to expand the work space to the top, back and bottom of the robot, and no stiffness problem side-mounted robot, resulting in widespread attention. This structure is not only suitable for light, but also for heavy-duty robots[2-3]. In recent years, spot welding robots (load 100-150kg) mostly chosen robot in the form of a parallelogram structure.

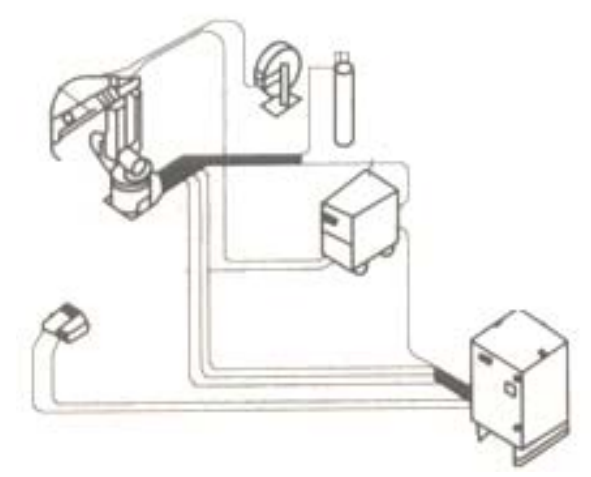

a) arc welding robot

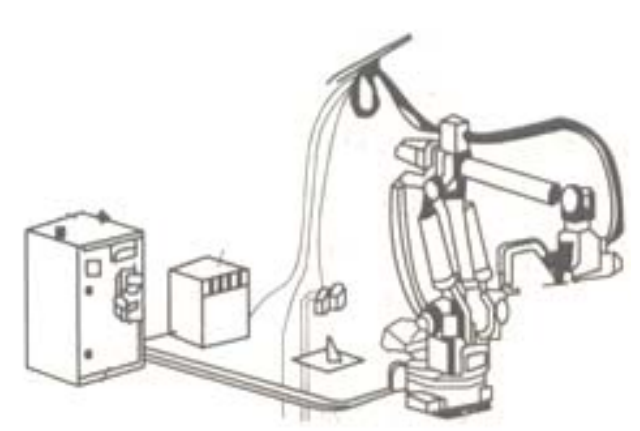

b) spot welding robot

Fig 1 consisting of welding robot

A new generation of welding robots are moving towards to intelligent direction, can automatically detect the thickness of the material, workpiece shape, welding trajectory and position, size and form of the groove, seam gap, etc., and automatically sets the welding specifications and parameters, torch movement points or track, filler wire or wire feed speed, welding clamp swing mode and so on; also available in real time to detect whether solder joints or welds required, whether internal or external welding defects, etc. The key of intelligent robots lies in the improvement and development of computer hardware and software capabilities, and a variety of high-performance, high-reliability sensors developed. Currently, many countries are engaged in development work in this area, so that the intelligent welding robot with visual, auditory, tactile functions application in production around the corner. 


\section{Computer applications in welding}

\subsection{Numerical simulation technology}

Numerical simulation technology is the use of a series of mathematical equations to describe the variation of the basic parameters of the welding process, and then solved using numerical calculation, and the entire process through is a computer presentation.

To determine the conventional welding processes rely on trial and experience, numerical simulation techniques can get a lot of complete data, and to reduce the error caused by the experimental methods, so that developed welding process scientific and reliable. If the temperature changes during welding, weld solidification process, welding stress and strain produced can be intuitive quantitative description by numerical simulation.

\subsection{Welding expert system}

Welding expert system is computer software to solve related questions the field of welding. It includes knowledge acquisition module, knowledge base, inference mechanism and man-machine interface. Knowledge acquisition module can achieve self-learning expert system, converted expert information and data information in the field of welding into a form computer can use, and stored in the knowledge base. Knowledge is an important part of the expert system, a full-rich knowledge base can be comprehensive and integrated analysis of expert system for problems encountered. Inference mechanism can be identification-selection for information about the current issues, match the knowledge base and get solutions to problems[4].

Welding expert system can analysis a lot of information and data for fast and accurate. Currently, a variety of welding expert systems has appeared in the field of welding, such as welding structural fracture safety assessment expert system, welding materials and welding technology expert system, and so on.

\subsection{Welding CAD/CAM system}

Welding $C A D / C A M$ systems are use of computer-aided design and manufacturing to control welder welding. $C A D / C A M$ integrated technology can be transfer and sharing $C A D$ and $C A M$ modules of different function scale and information with each other to achieve a high degree of integration of information processing.

$C A D / C A M$ welding system of $C N C$ welding robot is shown in fig2. There are Stored on the computer's internal operating procedures of welding technology, welding procedures, welding parameter adjustment procedures. First, we analysis welding current, voltage, welding speed, shielding gas flow and pressure welding parameters, summarized the best welding program with welding of different materials and structures, and then use the computer to control the welding robot to perform the most by a predetermined trajectory good programs for the welding process. Computer extracts the actual welding situation by the sensor, and compared, analyzed, and then the instruction is fed back to the power control system, wire feeder, gas flow valve, the drive means to adjusted by a digital to analog converter, so as to ensure the quality of welding. Output device also has a monitor TV, print and other equipment used to record the quality of the situation to show monitoring results.

\subsection{Improve welding productivity}

Improve welding productivity is an important driving force to promote the development of welding technology. Its approach has two aspects:

1)Improve weld deposition rate. Manual metal arc welding direct use of iron rod, gravity welding 
and other technology; multi-wire submerged arc welding, hot wire fall into this category, and its effect is significant. For example, three-wire submerged arc, the process parameters were $2200 \mathrm{~A} \times 33 \mathrm{~V}, 1400 \mathrm{~A} \times 40 \mathrm{~V}, 1100 \mathrm{~A} \times 45 \mathrm{~V}$, with a smaller cross-section groove, back with a baffle or liner, $50-60 \mathrm{~mm}$ steel penetration forming at once, welding speed reaches $0.4 \mathrm{~m} / \mathrm{min}$ or more, the deposition efficiency is more than 100 times the manual metal arc welding.

2) Reducing the cross-sectional area of the groove and the amount of deposited metal. The past 10 years, the most prominent achievement is narrow gap welding. It is based on gas shielded arc welding, using a single wire, double wire, three wire welding. Whatever the joint thickness, it can be used in the form of butt. Such as the plate thickness of $50-30 \mathrm{~mm}$, a gap of about $13 \mathrm{~mm}$, because the required amount of deposited metal is lower into several times, reducing the number of times, thus greatly improving productivity. How to ensure that both sides of the penetration and ensure automatic tracking arc center in the groove center line is narrow gap welding main technical key.In order to solve these two problems, a variety of different options has been developed in the world, there has been a varied narrow gap welding. Electron beam welding, laser welding and plasma arc welding can be butt joints, and not have to open the groove, which has been more widely used.

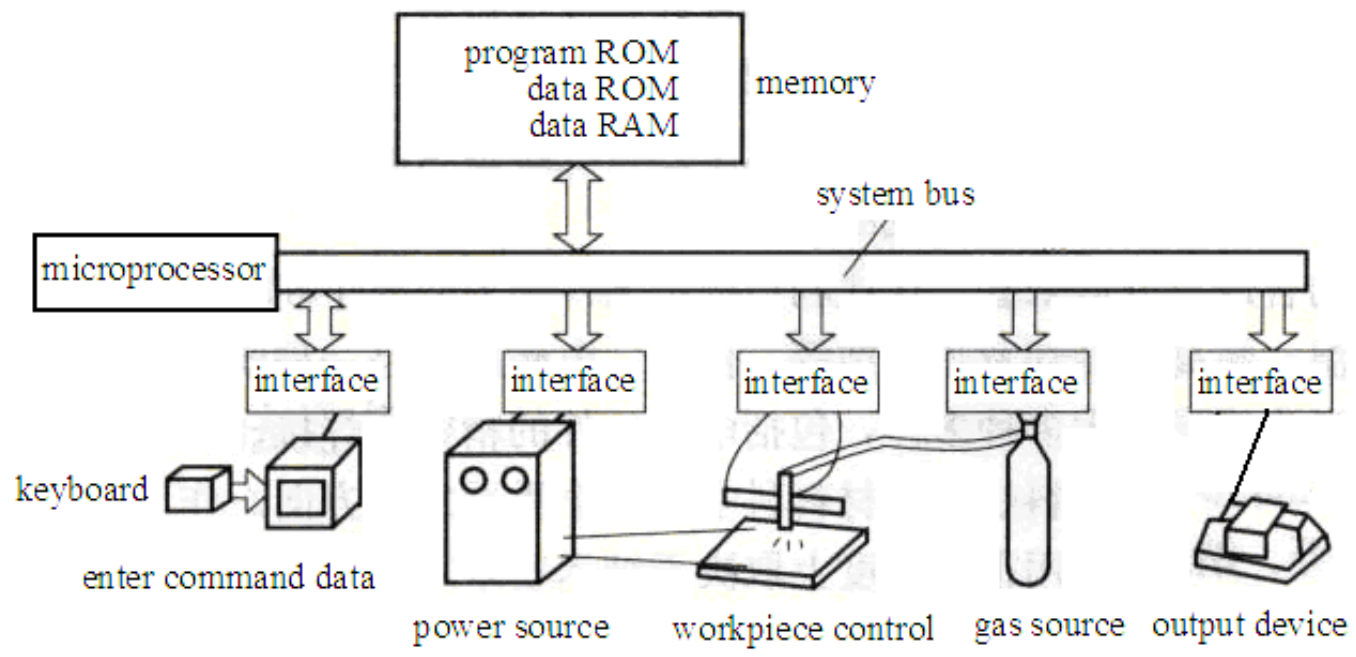

Fig 2 CAD/CAM welding system

\section{Development trend of modern forming technology}

With the advent of intermetallic compounds, superconducting materials, a variety of new functional materials and other new materials, traditional forming technology encountered new challenges. Correspond with preparation and synthesis of new materials, new forming method is becoming an important area of research and development of materials processing, preparation and process of materials integration is a developing trend.

According to the material forming processing technology may face the challenges and opportunities in the future, material forming technology will appear as a new feature: Precision feature, forming precision development to net shape (ie almost no margin forming) direction; quality characteristics, forming quality development to nearly defect-free direction; features fast, fast process of forming; complex features, method of forming development to the composite direction; green features, forming production to develop in the direction of cleaner production; information technology features and information technology form a high degree of integration.

From the point of view new synthetic materials and manufacturing, often take advantage of the extreme conditions as a necessary means. Such as high pressure, ultra-high temperature, ultra-high vacuum, extremely low temperatures, ultra-high-speed cooling and ultra-pure and so on[5].For 
example, electromagnetic forming is new methods both controllable shape and controllable material forming. Laser forming technology is diverse, including electronic components, precision micro-welding, automotive and marine casting welding, cutting and forming. Nanomaterials is an important development direction of modern materials science. as a new nano-materials structure and function, the application of its future depends largely on nano-powder parts forming technology development, in order to ensure the stability of the micro-structure of nanomaterials.

\section{Conclusion}

With the development of computer technology, Simulation based on the material forming technology become frontier and research focus of materials science and engineering disciplines. High-performance, high-fidelity and high efficiency is the effort goal of the simulation. After 40 years of continuous development,macroeconomic simulation of casting and forging process has been applied in the project.Multi-scale simulation in particular microstructure simulation is the new hot spot in recent years. Through computer simulations, it can be penetrate researched the structure of materials, composition and changes in the mechanism various physical and chemical processes in the macroscopic and microscopic, material composition, structure and prepare the best combination of material parameters is by design.

\section{References}

[1] Cao yongsheng,liu haijiang.Welding Robot Machining Path Optimization and Simulation. Chinese Mechanical Engineering,2010,04

[2] Welder P K.21stCentury Manufacturing[J].Prentice-Hall,Inc,2011,9-12.

[3] Liu Yin,Analysis of Welding Robots in Production Application Instances.Technology Innovation Herald,2010,06

[4] Xue Long.Based on Orbital Welding Robots Saddle Weld Technology Research,Welding Machines, 2012,01

[5] Chen Zhunian.Concise Manual Welding Design,Beijing,Machinery Industry Press; 2007, 2. 